\title{
Developing an Internet Attitude Scale for high school students
}

\author{
Chin-Chung Tsai ${ }^{\mathrm{a}, *}$, Sunny S.J. Lin ${ }^{\mathrm{a}}$, Meng-Jung Tsai ${ }^{\mathrm{b}}$ \\ ${ }^{a}$ Center for Teacher Education, National Chiao Tung University, 1001 Ta Hsueh Road, Hsinchu 300, Taiwan \\ ${ }^{\mathrm{b}}$ Center of Teacher Education, Tunghai University, Taichung 407, Taiwan
}

Received 13 September 2000; accepted 19 February 2001

\begin{abstract}
Although educators over the past decade have developed various scales measuring students' computer attitudes, few of them have constructed scales specifically for attitudes towards the Internet. The purpose of this study was to develop an Internet attitude scale for high school students. Through both revising a previous scale proposed by Selwyn (1997) [Selwyn, N. (1997). Students' attitudes toward computers: validation of a computer attitude scale for 16-19 education. Computers \& Education, 28(1), 35-41] and writing new items, this study developed an Internet Attitude Scale of 18 items, with the following four subscales: perceived usefulness, affection, perceived control, and behavior. This study also explored gender differences on the scale, and the relationship between Internet experience and students' responses on the scale. Research data gathered from 753 Taiwan high school students revealed that students of different gender and various Internet experiences did not show statistical differences on the perceptions toward the potential usefulness of the Internet subscale. However, male students tended to express more positive feeling, lower anxiety, and higher confidence toward using the Internet than female students. Students having more Internet experience tended to show similar positive attitudes than those of less experience. (C) 2001 Elsevier Science Ltd. All rights reserved.
\end{abstract}

Keywords: Secondary education; Gender studies; Internet attitudes; Taiwan

\section{Introduction}

Over the last few years, Internet technology has rapidly and dramatically influenced not only the manner of human communication, but also the mediation of teaching and learning (Havick, 2000; Tsai, 2000). Many researchers began to notice and to explore the unique features of the Internet. For example, Wagner and Wagner (1997) characterized the Internet by its dynamic

* Corresponding author. Tel.: + 886-3-5731671; fax: + 886-3-5738083.

E-mail address: cctsai@cc.nctu.edu.tw (C.-C. Tsai).

0360-1315/01/\$ - see front matter (C) 2001 Elsevier Science Ltd. All rights reserved.

PII: S0360-1315(01)00033-1 
nature, breadth of available resources, and the ease of getting information. Others attempted to put Internet literacy into the definition of computer literacy (Turner, Sweany, \& Husman, 2000). In contemporary and future societies, it is clear that Internet literacy plays and will play an essential role for all citizens to become information literate and lifelong learners. Preparing students for the knowledge and skills of Internet applications has also been recognized as an important goal of computer literacy education in the school curriculum (International Technology Education Association, 1996).

Just as the role of computer attitude is defined in computer literacy (e.g. Tsai, 1999), Internet attitude should be regarded as a component of Internet literacy. Students' attitudes towards the Internet may influence their motivation and interests towards learning to use the Internet, or vice versa (Coffin \& MacIntyre, 1999). As previous literature has suggested that students' attitudes toward computers have interactions with their performance of using and learning computers (e.g. Houle, 1996), students' Internet attitudes may also have interactions with students' performance in employing Internet technology. Moreover, female and male students may have different attitudes towards the Internet, including usefulness, affection, and behaviors. Although there are several scales of measuring students' computer attitudes developed by educators (e.g. Francis, Katz, \& Jones, 2000; Selwyn, 1997), due to the unique characteristics of the Internet, which are different from computers that work alone (for example, information sharing and interactive communication), the above comments and hypotheses need to be further investigated and explored. However, if an instrument for measuring Internet attitudes is not available, these research questions will not be answered.

The Internet has been recognized as producing the 4th industrial revolution in human history (Capron, 1999). In the twenty-first century, citizen's attitudes toward using and learning the Internet may determine the educational and economical development of a society. Students' Internet attitudes may impact their future involvement in Internet-related careers or activities. Assessing students' Internet attitudes with validity and reliability is necessary for future Internetrelated research. Most existing computer attitude scales are no longer as relevant to today's students who have grown up in an Internet-saturated society. Therefore, the purpose of this study was to develop the Internet Attitude Scale (IAS) by both revising a previous computer attitude scale and adding new items. Variables including gender and Internet using experiences were also analyzed in this study.

\section{The development of the IAS}

To develop the Internet Attitude Scale (IAS), a pool of items was collected by mainly adapting items from Selwyn's (1997) computer attitude scale and writing new items. Selwyn proposed the following four subscales for computer attitudes: affection, perceived usefulness, perceived control and behavior, including a total of 21 items. The items developed in this study were mainly based upon these items, and this study changed the term "computers" in the scale items into "the Internet." For example, the item "Computers make me feel uncomfortable" was reworded into "The Internet makes me feel uncomfortable." Besides, the authors developed 11 additional items for the initial pool of items. These items were included after consulting with some experts in Internet technology and technology education. Many of these new items were statements 
addressing the special features of Internet. For example, the items like "The Internet enlarges my scope" and "The Internet helps me acquire relevant information I need" focused on the function of worldwide connections and information sharing provided by the Internet. As a result, the initial pool of items in the scale included a total of 32 items. These 32 items were then presented using a four-point Likert scale (from "strongly agree," "agree," "disagree" to "strongly disagree") to a group of Taiwan high school students for item analysis. ${ }^{1}$ All of the items were presented in Chinese. The translation between English and Chinese in this study was completed by one of the authors, and the rest of the authors validated the translation.

Approximately 1000 Taiwan high school students were selected as the participants of this study using cluster sampling. The population of high school students in Taiwan was clustered into three demographic areas: northern, central, and southern Taiwan. Eight schools were selected from the three areas. For each school, two to three classes were randomly selected to form the initial subject pool, i.e. of about 900 students. However, if a subject had never used the Internet, their data were excluded from further statistic analyses. This left 753 subjects in the final sample pool. The research data gathered from these students were used to explore their Internet attitudes, Internet dependence and some other related variables and the findings will be reported in a series of papers (e.g. Lin \& Tsai, in press). The focus of this paper is to report on one aspect of this research, the development of the Internet attitude scale. Since there were more male students that had experiences of using the Internet, the final sample was about $67.5 \%$ male. The evidence that more males than females used the Internet corresponds to Internet usage research conducted worldwide (e.g. Griffiths, 1998).

For students' non-responses, unintentional skips or unidentifiable marks on some items of the initial version of IAS, this study processed these as "missing" data. Hence, the valid number of student cases on each item or subscale of the attitude measurement varied. However, the "missing" data for any item or subscale, at most, counted for 3\% of the whole data set.

Factor analysis was then used on the data for item analysis. Selwyn (1997) used exploratory factor analysis, principle component analysis with varimax rotation, to clarify the structure of computer attitude scale. Subjects' attitudes towards computer can be distinctively grouped into four orthogonal factors, affective, perceived usefulness, perceived control, and behavioral components that accounted for $64.8 \%$ of total variance explained. Therefore, this study applied the same factor analysis method to deal with the current data set. ${ }^{2}$ The eigenvalues of the first four factors from principle component analysis were larger than one: $3.358,2.607,2.254$, and 1.466 (Table 1).

\footnotetext{
${ }^{1}$ Item stated in a reverse way was scored in a reverse way, described later.

2 One may argue that Internet attitudes and computer attitudes are different psychological phenomenon, then scale development for a new Internet attitude scale should begin with exploratory work identifying the key features of such attitudes. Internet surely has its distinctive features but in designing this scale, only the attitudes highly related with learning outcomes are addressed. In a longitudinal study, Klobas and Clyde (2000) investigated how attitudes associated with Internet learning. They found adults viewed Internet as a useful, interesting, relative advantage tool to get learning information and communicate with learning partners. Also, Internet attitudes, such as perceived usefulness, perceived control, intention of using Internet, and low anxiety were related to positive learning behaviors. Because this study was pilot in nature, the authors decided to limit the research scope on Internet attitudes concerning learning while other attitude factors concerning communication or social interaction - such as deindividualization in Joinson (1998) or flaming in Thompsen and Fulger (1996) - are not included in this study. Based on this reflection, we assumed the Internet attitude scale is composed of similar factor structure of computer attitude scale designed by Sel-
} 
Only four factors were retained in the final version of the scale and they accounted for $53.81 \%$ of variance. An item was retained only when it loaded greater than \pm 0.40 on the relevant factor and less than \pm 0.40 on non-relevant factor. Thus, the initial 32 items were reduced to 18 items. The retained items and responding subscales are shown in Table 2. A detailed description of the four subscales is presented below:

1. The perceived usefulness subscale: measuring students' perceptions about the positive impacts of the Internet on individuals and society.

2. The affection subscale: assessing students' feeling and anxiety when using the Internet.

3. The perceived control subscale: measuring students' confidence about the independent control of the usage of the Internet.

4. The behavior subscale: assessing students' actual practice and frequency of using the Internet.

The internal reliability index, alpha coefficients, were adequate for the first three subscales, $0.82,0.71$, and 0.68 , and for the entire scale, 0.81 . However, alpha $(0.49)$ was relatively low for the fourth scale, Internet use behavior. The poor internal consistency of the behavior subscale

Table 1

Rotated factor loadings and Cronbach's $\alpha$ values for the four factors (subscales) of the Internet Attitude Scale ${ }^{\mathrm{a}}$

\begin{tabular}{llll}
\hline Item & Factor 1: & Factor 2: & Factor 3: \\
& Perceived usefulness & Affection & Perceived control \\
\end{tabular}

Factor 1: Perceived usefulness $\alpha=0.82$

$\begin{array}{ll}14 & 0.640 \\ 22 & 0.727 \\ 26 & 0.752 \\ 30 & 0.749 \\ 32 & 0.780\end{array}$

Factor 2: Affection $\alpha=0.71$

$5 \quad 0.649$

$17 \quad 0.701$

$21 \quad 0.657$

$25-0.588$

$29 \quad 0.625$

Factor 3: Perceived control $\alpha=0.68$

3

$15-0.610$

$19-0.573$

$23 \quad 0.691$

$27 \quad 0.763$

Factor 4: Behavior $\alpha=0.49$

8

16

20

$\begin{array}{lrrrr}\text { Eigen value } & 3.358 & 2.607 & 2.254 & 1.466\end{array}$

$\%$ Of variance

18.66

14.48

12.52

8.15

a Overall $\alpha=0.81$, total variance explained is $53.81 \%$. 
may be caused by the relative small number of items (three items) in the scale. Or, maybe the wording of those statements needs further modification. Table 3 further showed the inter-correlation matrix among four subscales. Because all the correlations reached significant level of 0.01 , the four factors measure Internet attitude in a coherent way.

Table 2 shows that some items in the IAS were scored in a reverse manner. In this way, students having higher scores on the scale showed better attitudes and higher confidence toward

Table 2

Retained items on the Internet Attitude Scale

\begin{tabular}{|c|c|c|}
\hline Item No. ${ }^{\text {a }}$ & Subscale & Question \\
\hline 14 & Perceived usefulness & The Internet can allow me to do more interesting and imaginative work \\
\hline 22 & Perceived usefulness & The Internet enlarges my scope ${ }^{b}$ \\
\hline 26 & Perceived usefulness & The Internet makes a great contribution to human life ${ }^{b}$ \\
\hline 30 & Perceived usefulness & The Internet helps me acquire relevant information I need ${ }^{b}$ \\
\hline 32 & Perceived usefulness & The Internet makes society more advanced ${ }^{\mathrm{b}}$ \\
\hline 5 & Affection & I hesitate to use the Internet in case I look stupid ${ }^{c}$ \\
\hline 17 & Affection & $\begin{array}{l}\text { If given the opportunity to use the Internet I am afraid that I might damage } \\
\text { it in some wayc }\end{array}$ \\
\hline 21 & Affection & The Internet makes me feel uncomfortable ${ }^{c}$ \\
\hline 25 & Affection & I feel bored toward using the Internet ${ }^{b, c}$ \\
\hline 29 & Affection & When using the Internet, I am not quite confident about what I am doing ${ }^{\mathrm{b}, \mathrm{c}}$ \\
\hline 3 & Perceived control & $\begin{array}{l}\text { I could probably teach myself most of the things I need to know about } \\
\text { the Internet }\end{array}$ \\
\hline 15 & Perceived control & I need an experienced person nearby when I use the Internet ${ }^{c}$ \\
\hline 19 & Perceived control & $\begin{array}{l}\text { If I get problems using the Internet, I can usually solve them one way or } \\
\text { the other }\end{array}$ \\
\hline 23 & Perceived control & I do not need someone to tell me the best way to use the Internet \\
\hline 27 & Perceived control & I can use the Internet independently, without the assistance of others ${ }^{b}$ \\
\hline 8 & Behavior & I only use the Internet at schools when told to ${ }^{c}$ \\
\hline 16 & Behavior & I use the Internet regularly throughout school \\
\hline 20 & Behavior & I spend much time on using the Internet ${ }^{\mathrm{b}}$ \\
\hline
\end{tabular}

a The item number indicates the item order in the initial version of the IAS (a total of 32 items).

b Not modified from Selwyn's (1997) scale.

c Scored in a reverse way

Table 3

Inter-correlation matrix of four Internet attitude factors

\begin{tabular}{llll}
\hline Internet Attitude Factors & Perceived usefulness & Affection & Perceived control \\
\hline Perceived usefulness & - & & \\
Affection & $0.407^{* *}$ & - & \\
Perceived control & $0.279^{* *}$ & $0.287^{* *}$ & - \\
Behavior & $0.260^{* *}$ & $0.197^{* *}$ & $0.406^{* *}$ \\
\hline
\end{tabular}

$* * P<0.01$ 
using the Internet. However, it should be noted that the final scale of 18 items was not completely balanced for direction of answering (e.g. only seven of the 18 items were stated in a reverse way).

\section{Students' scores on the Scale}

Table 4 further presents students' average total scores and standard deviations on the four subscales. A further examination about mean differences among four subscales is presented in Table 5. Students scored highest on the perceived usefulness subscale (an average of 3.38 per item, i.e. 16.90/5) and followed by the affection subscale (an average of 3.19 per item), the perceived control subscale (an average of 2.62 per item), and the behavior subscale (an average of 2.53 per item, i.e. 7.59/3). These results imply that students, in general, tended to appreciate the potential usefulness and show positive feeling in using the Internet. The relatively lower scores on the perceived control and behavior subscales suggest that some of the students might have had either real or perceived difficulties in controlling the Internet. This is the classic 'lost in cyberspace' feeling that has been documented in hypermedia studies.

\section{Gender differences on the scale}

This study further compared male and female students' scores on the four subscales of the IAS. The results of $t$-tests are presented in Table 6 . Table 6 reveals that male and female students' scores on the perceived usefulness subscale did not show statistical differences at the 0.05

Table 4

Students' scores on the subscales of Iinternet Attitude Scale

\begin{tabular}{llllll}
\hline Subscale & Items & Possible range & Range (actual) & Mean & S.D. \\
\hline Perceived usefulness & 5 & $5-20$ & $5-20$ & 16.90 & 2.37 \\
Affection & 5 & $5-20$ & $5-20$ & 15.96 & 2.24 \\
Perceived control & 5 & $5-20$ & $7-20$ & 13.11 & 2.49 \\
Behavior & 3 & $3-12$ & $3-12$ & 7.59 & 1.65 \\
\hline
\end{tabular}

Table 5

Paired $t$ tests for the means of four scales

\begin{tabular}{llllr}
\hline & Mean difference & S.D. & d.f. & $t$ value \\
\hline Usefulness-affection & 0.192 & 0.502 & 731 & $10.36^{* * *}$ \\
Usefulness-control & 0.761 & 0.581 & 734 & $35.58^{* * * *}$ \\
Usefulness-behavior & 0.850 & 0.625 & 734 & $36.88^{* * *}$ \\
Affection-control & 0.570 & 0.567 & 727 & $27.12^{* * *}$ \\
Affection-behavior & 0.660 & 0.640 & 728 & $27.87^{* * *}$ \\
Control-behavior & 0.099 & 0.574 & 731 & $4.33^{* * *}$ \\
\hline
\end{tabular}

$* * * P<0.001$ 
Table 6

Gender comparisons on the subscales of Internet Attitude Scale

\begin{tabular}{llllll}
\hline Subscale & Gender & Mean & S.D. & $t$ & Probability \\
\hline Perceived usefulness & Male & 17.02 & 2.35 & 1.94 & 0.053 \\
Affection & Female & 16.66 & 2.36 & & \\
& Male & 16.14 & 2.23 & $3.05^{* *}$ & 0.002 \\
Perceived control & Female & 15.60 & 2.24 & & \\
\multirow{2}{*}{ Behavior } & Male & 13.55 & 2.38 & $7.15^{* * *}$ & 0.000 \\
& Female & 12.20 & 2.47 & & \\
& Male & 7.74 & 1.63 & $3.64^{* * *}$ & 0.000 \\
\hline
\end{tabular}

$* * P<0.01$.

$* * * P<0.001$.

significance level. That is, both male and female students perceived similar levels of usefulness of the Internet, and their high scores suggested that both male and female students believed in the potential usefulness of Internet. However, on the affection, perceived control, and behavior subscales, male students expressed statistically more positive attitudes towards the Internet than female students did. In other words, male students showed lower anxiety and higher confidence when using the Internet than female students did. Male students were also likely to use the Internet more frequently than female students. ${ }^{3}$

\section{Internet experience and Internet attitudes}

This study, moreover, analyzed the relationships between students' Internet attitudes and their Internet experience. Internet experience defined in this study is the length of time from the time of the student's first usage of the Internet to that of answering the IAS. This study divided the sample students into five groups of different levels of Internet experience: less than 1 year, 1-2 years, 2-3 years, 3-4 years, and finally more than 4 years. ${ }^{4}$ In the sample, about $42 \%$ of the students had used the Internet for less than 1 year, 36\% for $1-2$ years, $15 \%$ for $2-3$ years, 5\% for $3-$ 4 years, and $2 \%$ for more than 4 years. Table 7 shows an analysis between different Internet experience groups and their Internet attitudes. The ANOVA tests revealed that Internet experience played a role on IAS's subscales of affection, perceived control and behavior. However, students of various Internet experiences did not express significantly different perceptions about the potential usefulness of Internet. Through a series of Scheffe tests (Post Hoc tests), it was found that students having a longer time of exposure to the Internet tended to have statistically higher scores on the affection, perceived control and behavior subscales. Francis, Katz, and Jones

\footnotetext{
${ }^{3}$ It might be worth commenting that the gender differences, whilst significant, may not be very large in absolute terms.

4 One may believe that current Internet usage might be a better indicator than a crude measure of time of first usage in representing students' Internet experience. In fact, the authors tried to ask students to report their weekly Internet usage when developing the scale; however, some students responded invalid estimation (e.g. more than 100 hours a week). Hence, the authors decided to use their time of first usage to represent their Internet experience.
} 
Table 7

An analysis of Internet experiences and Internet attitudes

\begin{tabular}{lllll}
\hline Internet experiences & $\begin{array}{l}\text { Perceived usefulness } \\
\text { (mean, S.D.) }\end{array}$ & $\begin{array}{l}\text { Affection } \\
\text { (mean, S.D.) }\end{array}$ & $\begin{array}{l}\text { Perceived control } \\
\text { (Mean, S.D.) }\end{array}$ & $\begin{array}{l}\text { Behavior } \\
\text { (mean, S.D.) }\end{array}$ \\
\hline (1) Less than 1 year & $16.63(2.29)$ & $15.57(2.10)$ & $12.53(2.16)$ & $7.22(1.54)$ \\
(2) 1-2 years & $17.17(2.28)$ & $16.07(2.17)$ & $13.19(2.38)$ & $7.73(1.63)$ \\
(3) 2-3 years & $16.96(2.56)$ & $16.57(2.16)$ & $13.80(2.80)$ & $8.05(1.73)$ \\
(4) 3-4 years & $17.35(2.20)$ & $16.91(2.18)$ & $14.47(3.01)$ & $7.79(1.74)$ \\
(5) More than 4 years & $17.20(2.37)$ & $15.40(4.58)$ & $16.07(1.75)$ & $9.00(1.96)$ \\
$F$ (ANOVA) & 2.34 & $6.46^{* * *}$ & $15.49^{* * *}$ & $9.74^{* * *}$ \\
Scheffe test & & $(3)>(1)$ & $(5)>(2)>(1)$ & $(5)>(1)$ \\
& & $(4)>(1)$ & $(5)>(3)>(1)$ & $(3)>(1)$ \\
& & $(4)>(1)$ & $(2)>(1)$ \\
\hline
\end{tabular}

$* * * P<0.001$.

(2000) proposed that the construct validity of computer attitude scales could be demonstrated by a (positive) correlation to previous computer-related experiences. Thus, the significant relationships between students' Internet experiences and many subscales of the IAS in this study may provide evidence about the construct validity of the IAS. These relationships indicated that students having more Internet experience tended to express more positive feeling, lower anxiety, and higher confidence when using the Internet. Especially, the Scheffe tests indicated that Internet experience was highly related to students' perceptions of independent control of using the Internet. Increased Internet experience may greatly help students build confidence towards using the Internet. It is also plausible to find that students' Internet experience was positively related to their actual practice and frequency of using the Internet (i.e. the behavior subscale).

Both the gender comparisons and Internet experience comparisons revealed that students of different gender and various Internet experiences did not show statistical differences on the perceived usefulness subscale, but they did display significant differences on the rest of the three subscales. Students' perceptions about the usefulness of the Internet may be independent of their gender and Internet experiences.

\section{Discussion}

The results of this study revealed that male students, in many subscales, had more positive Internet attitudes than female students. The functions and features of the Internet are different from computers that work alone without connections; however, similar phenomena existed in terms of gender difference in attitudes toward these media and technologies. Although some researchers have argued that females' computer attitudes varied with age in terms of comfort, efficacy, and control over computers (Czaja \& Sharit, 1998; Levin \& Gordon, 1989), previous research concerning gender difference in computer-related attitudes, in general, has shown that male students had more positive attitudes towards computers - including anxiety, confidence, and liking — than female students (AlJabri, 1996; Robertson, Calder, Fung, Jones, \& O'Shea, 
1995). This study provided essential parallel evidence when research shifted the focus of analyses from computer attitudes to Internet attitudes. This study further suggests that the gender differences in Internet attitudes may exist as early as in the high school stage. However, the findings of this study revealed that both male and female students held similar perceptions about the usefulness of Internet.

Users' prior computer experience, especially the time of exposure, was another variable the computer-related research has paid much attention to. The impact of Internet experience on students' Internet attitudes revealed by this study was parallel to the impact of computer experiences on students' attitudes toward computers found in the research literature (e.g. Houle, 1996; Levin \& Gordon, 1989; Smith, Caputi, \& Rawstorne, 2000). Students with longer Internet exposure time, in general, had more positive attitudes toward the Internet. Czaja and Sharit (1998) even claimed that, both males and females, increased experiences with computers resulted in more positive attitudes for all people across most attitude dimensions. They further asserted that computer attitudes are modifiable for people of all age groups and the nature of computer experiences had an impact on attitude change. The present study indicated that students' prior Internet experience played an important role on their Internet attitudes, and providing appropriate Internet experiences may be a useful way to change students' Internet attitudes in a more satisfactory direction. The findings derived from this study suggested that Internet experience was positively related to students' affection, perceived control and behavior of using the Internet. Increased positive Internet experiences may help students shape better attitudes towards the Internet, especially for those who showed high anxiety and low confidence in using the Internet.

In summary, findings derived from this study mostly paralleled what had been found in prior computer-related attitude research. Male students showed more positive Internet attitudes than female students did; and, students with more Internet experiences tended to have better Internet attitudes. Since the Internet will be one of the main technologies surrounding all people's future life and learning environment, and people's attitudes do affect their technology utilization (AlKhaldi \& AlJabri, 1998), measuring Internet attitudes with validity and reliability is an important issue in Internet-related research. This study could be viewed as one of the beginning attempts on this. The next step of this study should work on providing more strong evidence about the validity of the IAS scale or making further modification. For instance, new items may be necessary to improve the consistency of the behavior subscale. In addition, this pilot study applied exploratory factor analysis to verify the structure of a new Internet attitude scale. We encourage future study to use confirmatory factor analysis approach (Bentler \& Bonett, 1980; Joreskog \& Sorbom, 1988; Rainer \& Miller, 1996; Valois et al., 2000) to further examine the validity and reliability of the newly developed Internet scale. Some issues also need more research to reach final conclusion, such as whether Internet attitude can be best described by a higher order or first order model and factors were correlated or orthogonal.

Since the scale developed in this study was conducted in Chinese (though many items were modified from a relevant English-based version), researchers of different language and cultural backgrounds are encouraged to adapt the scale to further examine its reliability and validity and then conduct some comparative analyses. Brosnan and Lee (1998) have reported a cultural difference between the West and the East college students concerning gender differences in computer attitudes and anxieties. Similar attempts about students' Internet attitudes can be conducted in the future. Future study should also develop some other attitude subscales that respond to the 
unique features of the Internet, for instance, attitudes towards social-oriented online interactions and anonymous letters on the Internet. A careful exploration of students' attitudes in these areas may provide more insights into how the use of the Internet is perceived and practiced by students.

\section{Acknowledgements}

The authors would like to thank the National Science Council of Taiwan, R.O.C., for financially supporting this research under Contract Nos. NSC 89-2520-S-009-010 and NSC 89-2511-S009-007-N. The authors also express their gratitude to two anonymous referees for their helpful comments on an early version of this paper.

\section{References}

AlJabri, I. M. (1996). Gender differences in computer attitudes among secondary school students in Saudi Arabia. Journal of Computer Information Systems, 37(1), 70-75.

AlKhaldi, M. A., \& AlJabri, I. M. (1998). The relationship of attitudes to computer utilization: new evidence from a developing nation. Computers in Human Behavior, 14(1), 23-42.

Bentler, P. M., \& Bonett, D. G. (1980). Significance tests and goodness of fit in the analysis of covariance structures. Psychological Bulletin, 88, 588-606.

Brosnan, M., \& Lee, W. (1998). A cross-cultural comparison of gender differences in computer attitudes and anxieties: the United Kingdom and Hong Kong. Computers in Human Behavior, 14(4), 559-577.

Capron, H. L. (1999). Computers: tools for an information age (2nd ed). New York: Addison-Wesley.

Coffin, R. J., \& MacIntyre, P. D. (1999). Motivational influences on computer-related affective states. Computers in Human Behavior, 15(5), 549-569.

Czaja, S. J., \& Sharit, J. (1998). Age differences in attitudes toward computers. Journal of Gerontology Series B-Psychological Sciences and Social Sciences, 53(5), 329-340.

Francis, L. L., Katz, Y. J., \& Jones, S. H. (2000). The reliability and validity of the Hebrew version of the computer attitude scale. Computers \& Education, 35(2), 149-159.

Griffiths, M. (1998). Internet addiction: does it really exist? In J. Gackenbach, Psychology and the Internet: intrapersonal, interpersonal, and traspersonal implications (pp. 61-75). San Diego, CA: Academic Press.

Havick, J. (2000). The impact of the Internet on a television-based society. Technology in Society, 22(2), 273-287.

Houle, P. A. (1996). Toward understanding student differences in a computer skill course. Journal of Educational Computing Research, 14(1), 25-48.

International Technology Education Association (1996). Technology for all Americans: a rationale and structure for the study of technology. Reston, VA: International Technology Education Association.

Joinson, A. (1998). Causes and implications of disinhibited behavior on the Internet. In J. Gackenbach, Psychology and the Internet: intrapersonal, interpersonal, and transpersonal implications (pp. 43-60). San Diego, CA: Academic Press.

Joreskog, K. G. \& Sorbom, D. (1988). LISREL 7: A guide to the program and applications. Chicago: SPSS.

Klobas, J. E., \& Clyde, L. A. (2000). Adults learning to use the Internet: a longitudinal study of attitudes and other factors associated with Internet use. Library and Information Science Research, 22(1), 5-34.

Levin, T., \& Gordon, C. (1989). Effect of gender and computer experience on attitudes toward computers. Journal of Educational Computing Research, 5(1), 69-88.

Lin, S. S. J., \& Tsai, C.-C. (in press). Sensation seeking and Internet dependence of Taiwanese high school adolescents. Computers in Human Behavior.

Rainer, R. K., \& Miller, M. D. (1996). An assessment of the psychometric properties of the computer attitude scale. Computers in Human Behavior, 12(1), 93-105.

Robertson, S. I., Calder, J., Fung, P., Jones, A., \& O'Shea, T. (1995). Computer attitudes in an English secondary school. Computers \& Education, 24(2), 73-81. 
Selwyn, N. (1997). Students' attitudes toward computers: validation of a computer attitude scale for 16-19 education. Computers \& Education, 28(1), 35-41.

Smith, B., Caputi, P., \& Rawstorne, P. (2000). Differentiating computer experience and attitudes toward computers: an empirical investigation. Computers in Human Behavior, 16(1), 59-81.

Thompsen, P. A., \& Fulger, D. A. (1996). Effects of pictographs and quoting on flaming in electronic mail. Computers in Human Behavior, 12(2), 225-243.

Tsai, C.-C. (2000). A typology of the use of educational media, with implications for Internet-based instruction. Educational Media International, 37, 157-160.

Tsai, M. J. (1999). The impact of strategic and cooperative learning on Taiwanese eighth graders' computer achievement, attitudes, and anxiety. Unpublished doctoral dissertation, The University of Texas at Austin, TX.

Turner, G. M., Sweany, N. W., \& Husman, J. (2000). Development of the computer interface literacy measure. Journal of Educational Computing Research, 22(1), 37-54.

Valois, P., Frenette, E., Villeneuve, P., Sabourin, S., \& Bordeleau, C. (2000). Nonparametric item analysis and confirmatory factorial validity of the computer attitude scale for secondary students. Computers \& Education, 35(4), 281294.

Wagner, P. D., \& Wagner, T. A. (1997). The World Wide Web in the classroom: access without adult material. The Technology Teacher, 56(5), 22-25. 